This item was submitted to Loughborough's Research Repository by the author.

Items in Figshare are protected by copyright, with all rights reserved, unless otherwise indicated.

\title{
Sport for development and transformative social change: the potential of Margaret Archer's Morphogenetic Approach to reconceptualize a long- standing problem
}

\section{PLEASE CITE THE PUBLISHED VERSION}

https://doi.org/10.1123/ssj.2020-0112

\section{PUBLISHER}

Human Kinetics

\section{VERSION}

AM (Accepted Manuscript)

\section{PUBLISHER STATEMENT}

Accepted author manuscript version reprinted, by permission, from Sociology of Sport Journal, 2022, 39 (1): 78-87, https://doi.org/10.1123/ssj.2020-0112. (c) Human Kinetics, Inc.

\section{LICENCE}

CC BY-NC-ND 4.0

\section{REPOSITORY RECORD}

Lindsey, lain, and Gareth Wiltshire. 2021. "Sport for Development and Transformative Social Change: The Potential of Margaret Archer's Morphogenetic Approach to Reconceptualize a Long-standing Problem". Loughborough University. https://hdl.handle.net/2134/16652560.v1. 
This is an open access version of the following paper:

Lindsey, I., \& Wiltshire, G. (2021). Sport-for-development and transformative social change: The potential of Margaret Archer's Morphogenetic Approach to reconceptualise a longstanding problem. Sociology of sport journal. https://doi.org/10.1123/ssj.2020-0112

\title{
Sport for Development and Transformative Social Change: The Potential of Margaret Archer's Morphogenetic Approach to Reconceptualize a Long-Standing Problem
}

\author{
Iain Lindsey and Gareth Wiltshire
}

\begin{abstract}
Frequent calls for sport for development (SFD) to be reoriented toward transformative social change reflect the extent that policies and programs have instead focused on individualized forms of personal development. However, SFD research has yet to substantially address fundamental ontological assumptions and underlying conceptualizations of transformative social change. To addresses this gap, this article considers how Margaret Archer's Morphogenetic Approach can help explain how transformative social change might occur through SFD activities. Three conceptual contributions are brought into focus: (a) assuming a realist social ontology; (b) making distinctions between structure, culture, and agency; and (c) identifying social change as happening across three temporal phases. The authors conclude by identifying potential benefits and implications of applying the Morphogenetic Approach to consider the potential for SFD to contribute to social change.
\end{abstract}


Rapid expansion in the field of sport for development (SFD) since the start of the 21st century has been accompanied by widely shared concerns regarding the nature of the "development" that may be pursued through sport. Specifically, SFD policies and programs have been heavily critiqued as being predominately focused toward individualized forms of personal development for participants who are identified as being subject to deprivation and other inequalities (Hayhurst, 2009; Nols, Haudenhuyse, $\&$ Theeboom, 2017). As a result, reorientation of SFD toward the transformation of broader social conditions has been commonly and repeatedly advocated (Black, 2017; Darnell, 2012; Hartmann \& Kwauk, 2011). Given the prominence and importance of these issues, it is something of a surprise that the existing SFD literature has yet to substantially and explicitly consider the fundamental ontological assumptions and underlying conceptualization of transformative social change itself. That is, while the design and implementation of innovative SFD programs aiming to achieve transformative social change are undoubtedly a priority, we also suggest that research and analysis engaging with this work would benefit from novel analytical tools that can unpack what transformative social change entails. As the first SFD article that is oriented toward specifically addressing this ontological and foundational gap in the academic field, our aim is to consider the value of Archer's (1995) Morphogenetic Approach, a theory of social change grounded in critical realist scholarship.

The article commences by reviewing prominent contributions in the SFD literature that offer either conceptual advances related to social change or overarching analyses of this field. Doing so enables identification of key questions that need to be addressed in order to enhance understanding of how transformative social change may potentially come about. Our exposition of how the Morphogenetic Approach addresses these questions and subsequently proceeds through three steps. First, we explain the realist social ontology that underpins the Morphogenetic Approach. Second, we highlight the utility of distinguishing between structure, culture, and agency as foregrounded in the Morphogenetic Approach. Third, we identify the importance of temporality to the exposition of both social change (transformation) and social stability (reproduction) through the Morphogenetic Approach. Within each of these steps, we reexamine a selection of relevant empirical examples in the existing literature to help illustrate the potential of the Morphogenetic Approach to provide a new lens to advance analysis of SFD. The article then concludes by discussing resultant implications, possibilities, and challenges of the Morphogenetic Approach for researchers in the SFD field.

\section{Perspectives on Individual and Social Change in the SFD Literature}

Prominent critiques of the individualized focus of SFD programs often identify the prevalence of a "deficit-model" approach through which young people, especially, are targeted as potential beneficiaries to be "developed" because they are subject to, or are identified in, contexts of deprivation (Coakley, 2011; Coalter, 2013; Nols et al., 2017). For instance, programs may seek to address high 
levels of worklessness by seeking to improve individuals' employability skills (Suzuki, 2017) or reduce crime by using sport in seeking to inculcate particular values among "high-risk" young people (Hartmann \& Kwauk, 2011). While approaches may vary dependent on contextually relevant social issues, the key and common point is that SFD programs are often limited to supporting marginalized individuals and groups to "survive and move forward within existing social hierarchies" (Spaaij, Oxford, \& Jeanes, 2016, p. 584) rather than offering a means of "challenging the social and economic relations that abject individuals and groups" more systemically (Darnell \& Hayhurst, 2011, p. 190).

Rather than being the targets of change, societal and economic conditions are most commonly identified as constraints that shape SFD programs in different ways according to the particular case being examined. Research on international SFD programs that are oriented toward communities in the global South provides strongly developed critiques of the overbearing influence of funders, organizations, and practitioners from the global North as a result of their advantaged positionality within historical, social, and economic hierarchies (Black, 2017; Darnell, 2012; Hayhurst, 2009). While resistance against Northern influence has been identified by some researchers in the field (e.g., Lindsey, Kay, Jeanes \& Banda, 2017; McSweeney, Kikulis, Thibault, Hayhurst, \& van Ingen, 2019), SFD programs and participants have also been recognized to be constrained by more localized conditions. For example, Sherry et al. (2017) identified how cultural expectations of gender roles and attire affected women's SFD in the Pacific Islands, and Sabbe, Bradt, Spaaij, and Roose (2020) recognized the exclusionary stereotypes experienced by SFD participants in Flanders when they entered different community spaces.

Widespread recognition of these problems, and concerns that SFD may actually reproduce oppressive social structures (Black, 2017; Mwaanga \& Banda, 2014), has led to various leading authors calling for SFD to take a different and more "transformational" course:

A more radical interventionist approach [is needed], in which sport is intended to contribute to fundamental changes and transformations in social life. (Hartmann \& Kwauk, 2011, p. 287)

What is needed, therefore, is not the refined application of SFD but a re-imagining of SFD that challenges relations of dominance. (Darnell, 2012, p. 153)

Liberating SDP [Sport for Development and Peace] education should strive to promote authentic and lasting social change... facilitating transformative action in order to challenge broader social structures and power dynamics. (Spaaij \& Jeanes, 2013, p. 451)

Of course, transformative change of this kind is easier said than done. We are, nevertheless, wholly supportive of such calls but would argue that there has yet to be sufficient theoretical development within SFD in response to the challenge that transformational social change presents. This is a concern that has roots in a continuing and key theoretical divide within the SFD literature (Darnell, Giulianotti, Howe, \& Collison, 2018). Applications of critical, and predominantly sociological, theories have 
enabled important expositions of social, historical, and economic conditions that constrain SFD and those engaged with it, but have offered little purchase as yet for those who wish to understand whether and how SFD may contribute to transforming such conditions. On the other hand, normative theorizing within a broadly "instrumental" strand of SFD literature has primarily focused on developing and evaluating individual-level impacts (Lindsey et al., 2017). It is in attempting to overcome the limitations of exposition across both strands of literature that SFD scholars have, as both Darnell and Dao (2017) and Sabbe et al. (2020) identify, increasingly turned toward two particular theoretical approaches that engage with social change and transformation.

First, there has been increasing "momentum" toward utilization of Amartya Sen and Martha Nausbaum's Capabilities Approach within SFD (Dao \& Smith, 2019, p. 8). Zipp, Smith, and Darnell (2019), for example, argue that the Capabilities Approach aligns with a transformative vision for SFD, given its orientation toward "the interplay between social context and experiences and processes of development" (p. 447). Certainly, the Capabilities Approach gives attention to contextual "conversion factors" that may need to be altered so as to enable individuals to have freedom to realize their own desired forms of well-being (Suzuki, 2017; Svensson \& Levine, 2017). In this respect, Dao and Smith's (2019) articulation of the Capabilities Approach suggests that "development actors (e.g., governments, International NonGovernment Organisations, Non-Government Organisations) are responsible for providing the social and structural conditions for people to meet a minimum acceptable threshold of certain capabilities" (p. 7). Beyond this, however, SFD research grounded in the Capabilities Approach has yet to significantly engage with how such contextual conditions may be transformed (Darnell \& Dao, 2017). Moreover, the Capabilities Approach is centrally oriented toward the extent to which individuals have the opportunity to utilize the resources available to them (Svensson \& Levine, 2017). Thus, we share Darnell and Dao's (2017) concern that the central conceptual focus on personal capabilities "may not necessarily align with [a] transformative approach" (p. 33).

The second key theory that has underpinned consideration of transformative social change in SFD is Paulo Freire's Critical Pedagogy. Normatively, Freire's work is centered on developing people's "critical consciousness" such that they can work collectively and from the bottom-up to challenge structures of "domination and oppression" (Spaaij \& Jeanes, 2013). While SFD researchers have found empirical evidence and examples of educational practices that have led to increasing "critical consciousness" among SFD participants (Nols, Haudenhuyse, Spaaij, \& Theeboom, 2019; Oxford \& Spaaij, 2017; Spaaij \& Jeanes, 2013), they have also remained cautious about the extent to which Critical Pedagogy in SFD may bring about transformative change. Spaaij et al. (2016) identified that evidence of "transforming social structures remains elusive" (p. 584) and Oxford and Spaaij (2017) go further by questioning whether Freire's idealist vision of bottom-up development can actually disrupt the international and structural power relations that are intertwined in the contexts in which SFD programs and policies unfold. Conceptually, it is also important to recognize that Freire specifically 
abjures any generalized prescriptions for actions toward social transformation given his commitment to enabling people to understand and interrogate the context-specific structures of their own oppression in the first instance. This is a logically consistent position to take, but it is also one that leaves researchers with a significant challenge in identifying any common conceptions of what transformative change may entail.

While we recognize the excellence of some of the research that has considered and applied either the Capabilities Approach or the Freirean Critical Pedagogy to analyze SFD, it is our contention that conceptual gaps in the literature remain. Frequent and ongoing calls for further research into how SFD may potentially contribute to various forms of transformative social change (Black, 2017; Coakley, 2011; Darnell, 2012; Sabbe, Roose, \& Bradt, 2019) are an indicator not only of the practical challenge that the "problem of social change" poses but also, we argue, of the need for further attention to the theoretical tools available to inform analysis of any potential by which SFD may contribute to transformative social change. In particular, we are concerned by the lack of explicit debate in the SFD literature about the fundamental ontological assumptions and underlying conceptualization of transformative social change itself. That is, we see both the Capabilities Approach and Critical Pedagogy to be largely oriented toward normative purposes that offer crucial suggestions as to what ought to be done to achieve social change. What we see as missing from SFD literature and research, however, is a more analytically oriented framework that addresses basic questions of what transformative social change may actually be and entail. Such questions necessarily rest upon particular assumptions about the nature of the society, individuals, and the relationship between them. In other words, there is a need to consider ontological assumptions in this fundamental way so as to grapple with and develop clearer positions on the following questions:

- What is the nature of the "broader social conditions" that are the focus of calls for transformational change?

-What is the nature of the relationships between specific individuals and the broader social conditions that are intended to be transformed?

-What may be the nature of processes through which various desired forms of transformational change could actually come about?

\section{The Morphogenetic Approach as Applied to SFD}

\section{Realist Social Ontology}

Building the case for Archer's Morphogenetic Approach as a way of understanding potential transformative social change through SFD requires an appreciation of its grounding within the 
philosophical project of critical realism that is associated most closely with the work of Bhaskar (1975, 1979). Even though philosophical or "paradigmatic" assumptions are often left unconsidered or not always made clear by SFD researchers (Holt et al., 2017; Whitley et al., 2019), it is worth noting that distinct methodological traditions inform empirical investigations in the field. For example, the use of controlled experimental designs to assess whether or not a SFD program has had a significant effect on participants (e.g., Fuller et al., 2010) are associated with quite different ontological assumptions compared with the use of indepth interviews or ethnographic methods to explore the highly contextualized lived realities of participants (e.g., McSweeney \& van Luijk, 2019). In Schulenkorf, Edwards, and Hergesell's (2020) recent article on research methods for SFD, these different methodological traditions are presented as being grounded in "positivist" and "interpretivist" paradigmatic assumptions, respectively, even though we recognize that not all SFD research fits neatly within this dichotomy.1 Mirroring what is widely understood outside of SFD literature (see Lincoln, Lynham, \& Guba, 2017), the perspective presented by Schulenkorf et al. (2020) suggests that there exists a natural alignment between methods used (i.e., qualitative vs. quantitative) and researchers' paradigmatic assumptions. Critical realist scholarship, in contrast, represents an attempt to overcome the limitations of both positivist and interpretivist paradigms by incorporating different elements of opposing methodological traditions appropriately and valuably within a single research project (Collier, 1994; Sayer, 1992).

In identifying the fundamental, defining principles of critical realism, it is important to recognize the range of articles, books, and online resources that do so in more detail than is possible here (see Archer, Bhaskar, Collier, Lawson, \& Norrie, 2013; Clark, MacIntyre, \& Cruickshank, 2007; Critical Realism Network, 2020; Danermark, Ekstrom, \& Jakobsen, 2005; The Centre for Social Ontology, 2020). Moreover, we also recommend critical realist research that has developed over time in the wider sport literature (see Byers 2013; Downward, 2005; Nichol, Hall, Vickery, \& Hayes, 2019; Wiltshire, 2018), even though specific application of the Morphogenetic Approach is limited to Lusted's (2018) study of policy implementation in grassroots English football. Summarizing such existing contributions, we take critical realism to be a position which stakes an epistemological claim that science (both natural and social) produces fallible and concept-dependent knowledge of phenomena in the world, yet maintains the ontological claim that a real world does nevertheless exist "out there" independently of scientists' knowledge of it. This acknowledges that research accounts represent uncertain attempts at understanding the objective world - or what is true-but recognizes that our understanding can be improved because "the 'real world' constrains the interpretations we can reasonably make of it" (Wong, Greenhalgh, Westhorp, \& Pawson, 2012, p. 91).

Beyond this starting point, key authors (Archer, 2003; ElderVass, 2010; Porpora, 2015) have proceeded to bridge the gap between critical realism as a philosophy of science and a "realist social ontology" that provides a framework for understanding how transformative social change could occur. Building on 
critical realist foundations, the Morphogenetic Approach begins with the philosophical foothold that what we call "society" or the "social world" is real, in that it exists independently of our research activities about it. Of course, society is "constructed" in the sense that all of its properties and powers are the result of the historical accumulation of events but, as Elder-Vass (2010) notes, we must be both social constructivists and realists in our thinking about society. As an illustrative example, we can recognize on the one hand that gendered expectations and cultural norms around sport are socially constructed in various ways across the world, but also that it is objectively true that (in many if not necessarily all contexts) females suffer exclusion from sport to a greater extent than males (Spaiij et al., 2014). Indeed, to amend an example from Archer (1995), the very real dearth of literacy, health literacy, or physical literacy in a particular nation would exert its effects regardless of whether that dearth or its causes are known about or not.

A realist social ontology further entails a commitment to the notion that societies should be seen as possessing properties that are irreducible to the individuals that constitute their component parts. Because individuals have the capacity to cooperate and communicate, we can arrange ourselves in particular ways to form such things as sports clubs, charitable organizations, national governing bodies, and nation states. Thus, we collectively create entities with additional "emergent" properties and dispositions beyond those of the individuals that create them. In this respect, Bhaskar notes that "a tribesman implies a tribe, the cashing of a cheque a banking system" (Bhaskar, 1979, p. 28) just as, in various sports, a player implies a team and scoring implies a game. In this way, society is considered real and external to individuals but not deterministic. He explains that "we can allow that speech is governed by the rules of grammar without supposing either that these rules exist independently of usage (reification) or that they determine what we say" (Bhaskar, 1979, p. 36).

Crucially, Bhaskar's work to develop a Transformative Model of Social Activity and Archer's Morphogenetic Approach both demonstrate an appreciation of the causal powers held by societies, which neither reifies society nor treats it as merely the product of individuals' imaginations. As Porpora (2013) explains,

the Morphogenetic Approach completely supersedes the whole opposition between methodological individualism and sociological holism. In contrast with methodological individualism, people do not act apart from or outside of cultural and social structural contexts, and in contrast with sociological holism, the causal focus is on individual people enmeshed in a nexus of human relations, not on parts of a social system connected by functional relationships. (p. 29)

In developing a realist understanding of SFD, it is therefore important to recognize that societies are made up of "social formations" (such as families, schools, local governments, and charities) and that these possess properties and powers that individuals do not. The SFD organizations and programs are 
similarly recognizable as being social formations, which reminds us of the need to recognize their distinctive properties and powers both as they are initially created and as they become established over time. In this sense, Coalter (2010) invokes a realist social ontology in writing that SFD organizations "are consciously and systematically organized to maximize the possibility of achieving [developmental] outcomes" (pp. 1385-1386). On the other hand, as our earlier overview of the literature emphasized, social formations associated with SFD are also widely recognized to constrain the possibilities of development through sport. In a study that is novel in being specifically oriented by a realist perspective, Van der Veken, Harris, Delheye, Lauwerier, and Willems (2021) report constraints on SFD coaches' agency deriving from structures, which limit the extent of their professional recognition and status. A more widespread theme in the SFD literature recognizes that top-down control in SFD by donor organizations from the global North may sometimes - but by no means always-be realized through the actions of individuals (see, e.g., Darnell, 2012, on the role of volunteers working on behalf of international donors). In a similar regard, it is notable that Lusted's (2018) exposition of concerns regarding top-down governance, albeit in the different context of national and regional football organizations in the United Kingdom, are given strength by being framed and analyzed through an explicitly realist lens. We will return to some of Lusted's (2018) insights from his application of the Morphogenetic Approach in subsequent sections of the article.

\section{Clarifying the Distinctions Between Structure, Culture, and Agency}

In addition to the conception of a general realist social ontology, the Morphogenetic Approach also insists on making distinctions between a triad of concepts involved in explaining social change: structure, culture, and agency (see Figure 1). Archer frames her distinction between structure and agency as a response to what is referred to as the "central conflation" tendency whereby structure and agency become analytically inseparable (Archer, 1982). Often illuminating the distinctions between her approach and those of Bourdieu and Giddens, Archer (2003) contends that "'structure' and 'agency' are distinct strata of reality, as the bearers of quite different properties and powers" (p. 2). The distinction is made by treating structures firstly as the condition in which agents find themselves, and secondly as the consequence of the practical actions of agents. Agents have powers such as "thinking, deliberating believing, intending, loving and so forth" (Archer, 2003, p. 2), whereas structure possesses none of these powers, but can constrain and enable in ways that individuals cannot. Crucially in the context of this paper, an analytically distinct conception of agency is argued to be indispensable to a theory of social change. As Porpora (2013) simply puts it, "How do you explain social change without analytically distinct structures, without actors, without agency? You don't' (p. 33).

By separating out structure and agency in this way, Archer largely follows Bhaskar's understanding in that it is neither the social context nor the individual that is "determinant," but the interplay between 
them. Bhaskar (1979) writes that "people do not marry to reproduce the nuclear family or work to sustain the capitalist economy. Yet it is nevertheless the unintended consequence (and inexorable result) of, as it is also a necessary condition for, their activity" (p. 35).

Here, we can see that the overdetermination of social forms is avoided by attributing different properties and powers to individuals who, unlike social positions and relationships, have the capacity to reflect on the objective circumstance that they are in, make value judgments, and act according to particular motives, concerns, and projects. Agents and their social contexts interact but they are ontologically different.

Appreciation of how agents are distinct from structures already implicitly appears in various aspects of SFD, as highlighted by recognition of and intentions to develop reflexive capacities among participants and other stakeholders. In the SFD literature, we have already explored how educative approaches framed by Freirean Critical Pedagogy give central prominence to "fostering critical consciousness" as a prerequisite to begin to "challenge broader social structures" (Spaaij \& Jeanes, 2013). Further empirical attention has also primarily considered approaches to enhance the agency of persons directly involved in SFD programs, often focusing on young people as participants (e.g., Hoekman, Schulenkorf, \& Peachey, 2019; Nols et al., 2017), as peer leaders (e.g., Nichols et al., 2011; Lindsey et al., 2017), or as others in coaching or training roles (Scott, 2020; Van der Veken et al., 2021). However, it is not only those directly engaged in SFD programs who may potentially exercise, or be best placed to exercise, agency toward social change. Sugden (2010) proposes a model of a "ripple effect" through which stakeholders at different levels, from participants to those in "political society," may become involved in and contribute to change through SFD. Moreover, at an international level, Hayhurst (2009) strongly argues that it is the "perspectives of academics, United Nations agency executives, and International Olympic Committee officials" (p. 217) — rather than individuals involved in specific projects - that have the most significant influence on what she terms as the SFD "terrain." Therefore, in considering agency and social change in SFD, we must be mindful of Darnell's (2012) acknowledgement that individuals' agency is contextually situated in that "not all actors and stakeholders within [Sport for Development and Peace] enjoy the same relations of authority and privilege" (p. 152).

It is therefore important not only to recognize that agents and structures have distinct characteristics but also that different agents in SFD, who occupy different social positions, can have varying powers to transform or reproduce aspects of the social world. As various authors such as Kidd (2008), Lindsey et al. (2017), and Darnell, Field, and Kidd (2019) have described, the SFD movement has emerged over recent decades as constituted by various policies, organizations, and programs. None of these social forms are reducible to any specific collection of individuals but it remains the case that all have emerged as a result of the actions of agents working individually and collectively. A policy is created, developed, 
and written by agents, just as programs are designed and enacted by various people. Agents have done so in particular circumstances and through being reflective, perhaps to different extents, about the structural and cultural contexts to which their policies and programs relate. As a specific and welldescribed example, the creation of the Mathare Youth Sport Association in Kenya came through its founder, Bob Munro, reflecting on his encounters with material poverty in Nairobi's Mathare settlement as well as his reflections on his own experiences of youth sport in his native Canada (Darnell et al., 2019).

Another conceptual point that Archer asserts is that there are distinctions to be made between what we call "structure" and what we call "culture." We see this as particularly novel and significant because, as we identified earlier, there are various forms of social change that SFD may be oriented toward and, as such, researchers need to exercise discrimination and precision about the nature of social change that could transpire and be subject to investigation. On this point, Archer (2016) sees structure and culture as analytically distinct but causally related. She describes structural conditions as the "material" relations among social positions, such that "structures are objective, relational, interest-based and, crucially, they not only constrain and enable but also motivate people's intentionality and action" (p. 428). Hence, structure tends to refer to policies, institutions, organizations, social positions, and material resources, and they usually have the power to govern, make demands, and dominate (Case, 2015). In these terms, the recognition of structures is common in existing SFD research, most often in relation to the influence of institutionalized power and structured inequalities of wealth across the global North and South (e.g., McSweeney et al., 2019). Other examples, such as the specification of performance targets by which SFD may be measured (Harris \& Adams, 2016) or prescribed training manuals for use in SFD programs (Forde, 2014), represent structural forms that are established at and across different global, national, and local levels.

Archer's Morphogenetic Approach defines culture as distinct from structure by identifying that cultural conditions exist intersubjectively within collective ideas, beliefs, and opinions (Case, 2015). These are described as the "sum total of 'intelligibilia' (all elements with the dispositional capacity to be understood)" (Archer, 2016, p. 430) in acknowledgement of the notion that culture is public and collectively produced, and that its properties rely on whether or not they have been understood by individuals. Because culture relies more heavily on the involvement of subjects, it possesses different powers: those related to coercion, persuasion, and influence. As such, cultural conditions do-like structural conditions - produce motivations and intentions but they are altogether more like norms and expectations than laws and policies. In Porpora's (2013) words, "whereas structural motivations derive from the interests built into social positions, cultural motivations derive from people's value commitments and ultimate concerns" (p. 28). The importance of culture, thus constituted, needs no downplaying as Darnell (2012) specifically reminds us that SFD "may require coming to terms with 
sport as a cultural expression, one that is consistently (if not inextricably) politicized and negotiated socially" (pp. 145-146).

We would suggest that much of the, albeit limited, evidence of social change in the SFD literature represents cultural shifts of varying degrees and types, often in local contexts. For example, from his experience with the Mathare Youth Sport Association in Kenya, Coalter (2010) identifies that "the core value being emphasized here is that of collective responsibility and reciprocity" (p. 1380) - with these clearly being intersubjective norms. Cultural change in terms of disrupted "public perceptions" of traditional gendered relations was also identified in Seal and Sherry's (2018) research on SFD in Papua New Guinea. Similarly, and with particular resonance here, research undertaken by Spaaij et al. (2016) with a SFD program in Cameroon found that for young women, "convincing male community leaders to allow them to participate in football represents a shift in attitudes toward women but does not at this stage represent considerable changes to the position and status of women in the wider community" ( $p$. $582)$.

We can read such a quote through the lens provided by Archer's distinction as suggesting that a degree of cultural change has occurred (a shift in collective attitudes) but without concomitant, or resultant, changes in structural relations (the positionality of women in community institutions). Indeed, the localized focus of some African SFD nongovernmental organizations has been recognized as enabling change in community perceptions but hindering their influence within governmental structures and wider development policies (Lindsey et al., 2017). Archer (2013) herself draws on Bhaskar's image of the sculptor at work as a metaphor for practices of "chipping away" at existing structures and cultures and "carving out" new ways of organizing social forms. This conceptualization, combined with Archer's distinction between structure and culture, enables us to appreciate that

some materials are more resistant than others, that tools vary in their adequacy and that sociological identification of such differences is indispensable. What this is indispensable to is the key question, "when are we going to get transformation rather than reproduction, or vice versa?" (p. 360)

As such, we wish to suggest the value of the Morphogenetic Approach in sensitizing researchers to distinctions between agents, structure, and culture, and thereby enabling improved consideration of the different kinds of "things" that SFD may ultimately be seeking to transform.

\section{Morphogenesis/Morphostasis Cycles and Temporality}

Building on both the realist social ontology and the distinctions between structure, culture, and agency, we propose that the Morphogenetic Approach has additional value in explicitly introducing temporality to the conceptualization of social change. As the "methodological complement of critical realism's 
social ontology" (Archer, 2016, p. 248), the Morphogenetic Approach uses temporality to provide an explanatory framework that accounts for both social stability (reproduction) and social change (transformation). Borrowing a metaphor from biology, morphogenesis is the term used to describe "the complex interchanges that produce change in a system's given form, structure or state" (i.e., social change and transformation), whereas morphostasis is the process that leads to the maintenance of a system's given form, structure, or state (i.e., social stability and reproduction) (Archer, 1982, p. 458).

Archer (2013) proposes that it is essential to incorporate the element of temporality to understand how interactions between agency, structure, and culture result in morphogenesis or morphostasis. As she explains, societies have the potential to change precisely because of their discontinuity:

Necessarily, action is continuous ("no people: society") but because of their actions over time, structures are discontinuous (only relatively enduring) and once they are changed, then subsequent activities are conditioned and shaped quite differently (this society is not exclusively the product of those here present any more than future society is solely what our heirs produce). (p. 373)

So, while it is the case that the particular social behaviors and practices that are of interest to SFD programs - for example, sexual behavior in the case of sport and HIV programs - are dependent on structural and cultural circumstances at a given moment - for example, laws about age of consent, poverty, community values, and religious beliefs - the structure-culture-agency triad operates as an open system which is amenable to change. As individual agents (with varying positionality and levels of influence) interact with the social circumstances - for example, female community members sharing experiences of resisting pressure for sex, practitioners providing opportunities to access condoms, and/or policy makers creating new gender equality laws and regulations-they create new circumstances for future agents to operate within.

Fundamentally, Archer posits that structure and culture preexist individuals and it is this preexistence that establishes their autonomy from individuals and hence, the very possibility of change. This position therefore appreciates the importance of history, particularly in respect of reproduction. For example, in utilizing the Morphogenetic Approach to study grassroots football governance, Lusted (2018) specifically noted that,

The conditions I identified are not the exclusive property of the few who currently control the local game in England; they are long-standing relatively enduring and autonomous features, that are regularly reinforced by the routine forms of social interaction that help to reproduce them. (p. 716)

Temporality is modeled in the Morphogenetic Approach through the identification of three phases which provide the guidelines about how to analyze what might be going on in any context where SFD 
activities are implemented. As Archer (2013) explains, "preexistence and autonomy denote discontinuities in the structuring/ restructuring process which can only be grasped by making analytical distinctions between the 'before' (T1 ), the 'during' (T2 -T3 ) and 'after' (T4 )” (p. 359; see Figure 2). The three phases only progress if there is some interaction between people and their circumstances and, together, they make up one morphogenetic/ morphostatic cycle whose completion also represents the start of the next cycle (Archer, 2016).

To clarify, structural and cultural conditioning occurs in the first phase in the morphogenetic cycle (T1 ). Here, it is acknowledged that the current social and cultural conditions "are a result of past social interaction between agents, which condition the current context within which social agents operate" (Seal, 2016, p. 271). Conditioning is "not a 'law' or a 'force' but a reason" and we "enjoy interpretative freedom in respect to this" (Horrocks, 2009, p. 41). In this regard, albeit not from an explicitly realist account, Hasselgård and Straume's (2015) research illuminates the responses of local Zimbabwean staff, volunteers, and coaches in engaging with a SFD program that had been funded and largely designed by the Norwegian Confederation of Sport (known as NIF). These local stakeholder reflections centered on the structural orientation of the SFD program (as specified in specific documents) toward the reproduction of Norway's preexisting volunteer-centered community club system within Zimbabwe, as well as local particularities that included local geography, poverty, the absence of a volunteering culture, and the limited availability of school-based facilities. Thus, these conditions included a combination of structural and cultural elements, which gave local stakeholders reasons for their subsequent actions and approach to the program.

Agents' interactions with the structural and cultural conditions are what characterizes Phase 2 of the cycle (T2 - T3 ). Owing to the notion that structure and culture do not determine action, individuals go about their lives exploring inherited powers and boundaries "that we can adhere to, deconstruct or play with in the interaction stage" (Seal, 2016, p. 217). Continuing the example from Hasselgård and Straume's (2015) research, this social interaction phase of the morphogenetic/morphostasis cycle involved conduct among local agents (e.g., program staff, volunteers, and coaches who were interviewed in the research as well as those, such as parents, who were not) who had differential options to comply with, resist, or innovate within the structural and cultural conditions included in and associated with the Norwegian SFD program. This involves considerable reflexivity in the form of an internal conversation deliberating on personal concerns, projects, intentions, and the available options at a given time (Archer, 2003). Similarly, Hasselgård and Straume (2015, p. 98) notably refer to local stakeholders' responses as a "strategic act."

Phase 3 is characterized by either reproduction or transformation and can be seen as both an ending of one cycle and the start of a new cycle (T4 ). As Mirani (2013) puts it, 
performed action may transform the very system that predates and influences it, or, alternatively, reinforce and consolidate its premises. The former serves to accomplish morphogenetic change while the latter perpetuates morphostatis [sic], i.e., a continuation of the existing context and dynamics. (p. 664)

Porpora (2013) provides specific illustration of this morphogenetic process and outcomes through reference to the inventions of factory machinery during the Industrial Revolution. In this period, various industrial machines were agential innovations, which both drew their rationale from preceding conditions and subsequently served to radically alter widespread social and cultural contexts. While SFD activities are not of the same transformational significance, Hasselgård and Straume's (2015) research shows how local stakeholders' decisions and actions had differential results in terms of morphogenesis and morphostasis in both the particular SFD program and certain elements of Zimbabwe's sport system. They evidence how stakeholders' enactment of the program led to greater reproduction (i.e., morphostasis) of NIF's club-based SFD ideology in urban areas where "less traditional and contextual challenges" were encountered (Hasselgård \& Straume, 2015, p. 100) while, in other locations, there was transformation of the program itself by Zimbabwean stakeholders (i.e., morphogenesis) toward a more locally appropriate school-based system.

Archer's temporal framework also resonates with Sugden's (2010) articulation of the "ripple effect" by which he postulates that changes in "transcending social and policy context[s]" may emerge through initial SFD work with participants in local communities and then through effects over time on and through wider networks of stakeholders and organizations (p. 269). Occurring in this way, we could consider that moving out through each "concentric" ripple may represent a new morphogenetic cycle in which different sets of actors may reflect on structural and cultural changes that emerged from the last cycle and take further action, which thereby results in further aspects of morphogenesis and/or morphostasis. As stated previously, the "ripple model" valuably recognizes the roles of actors at different levels in these processes, and we would argue that it is also important to recognize the differential capacities of such actors to influence or reinforce different structural and cultural features from local to global levels over time.

The added value of the conceptualization of temporality in the Morphogenetic Approach resides in the analytic purchase it offers in differentiating what SFD researchers may "look for" and find across each of the three phases. The individualized forms of change primarily recognized and researched in SFD to date represent those that may occur through reflexivity and interaction in Archer's second phase. The key is that Archer differentiates such change temporarily and analytically from the structural and cultural change that we may find in Phase 3. Thus, evaluation of any potential transformative social change by the time that the third phase is reached would seek to identify the extent of any differences or similarities in structural or cultural conditions from those that ultimately "preexisted" particular SFD- 
related activity in Phase 1. We further consider the implications of this and other aspects of Archer's theorization for future SFD research in the following concluding section.

\section{Discussion and Conclusions}

Through this article, we have sought to demonstrate how the Morphogenetic Approach provides a suitable theoretical grounding for SFD research to advance understanding of how different forms of transformative social change may potentially come about. We recognize that Lusted (2018), through his research on football governance, similarly argues that "the Morphogenetic Approach is well suited to helping the researcher attempt to identify the generative mechanisms - the structures and powers in the realm of the 'real' that cause changes in the social world - that are specifically at play in shaping social action" (p. 711). In this final section, we draw on the preceding exploration of three connected conceptual contributions - (a) assuming a realist social ontology; (b) making distinctions between structure, culture, and agency; and (c) recognition that social change (or reproduction) happens across three temporal phases - to offer specific considerations and recommendations for future SFD research.

The value of the Morphogenetic Approach is fundamentally grounded in its basic assumption of a realist social ontology. As we have recognized, foundational ontological assumptions have rarely been explicitly foregrounded in previous SFD research and yet are essential to exploring and understanding the nature of potential social change and how it may come about. Moreover, it is the fundamentally analytic orientation of the Morphogenetic Approach that enables it to be offered as a novel analytic framework in comparison to those that have previously been advocated for use in considering social change through SFD. In this regard, Critical Pedagogy and the Capabilities Approach are respectively oriented toward particular means by which social change could be brought about and the desirable outcome of social change. SFD researchers have, therefore, advocated applications of these theorizations as normative ideal-types against which programs and practices may be compared (Dao \& Smith, 2019; Svensson \& Levine, 2017). A realist ontology and the Morphogenetic Approach is not necessarily incompatible with this type of analysis or the Capabilities Approach and Critical Pedagogy more generally. However, we would argue that the analytically neutral but ontologically based conception provided by the Morphogenetic Approach offers a wider framework for considering the range and diversity of forms of social change that may potentially be sought through SFD, as well as the different means and actors that may be involved in doing so.

In terms of specific implications drawn from the Morphogenetic Approach, we recommend that distinguishing between structure and culture could be of particular value in future SFD research. Expositions of the Morphogenetic Approach provide both broad definitions and specific features of structure and culture, which are applicable across multiple layers from the local to the global. Indeed, it may be a particularly rewarding research endeavor to examine SFD programs that navigate and 
potentially exploit incongruencies between aspects of structure and culture, given that Case (2015) indicates that

we need to consider whether the different aspects of culture and structure are in complementary or contradictory relations to each other. Here we can note that complementarities in either or both the structural and cultural domains are unlikely to give rise to change. It is rather within a situational logic of contradiction that morphogenesis is produced. (p. 244)

Deriving from our exploration of the Morphogenetic Approach, there would also be value in research that seeks to understand perspectives of types of agents whose particular structural or cultural positions may differentially accord them power to alter social conditions at different scales or different levels. In this regard, we would suggest that there is a need for SFD research to extend beyond the otherwise common focus on agents involved with particular programs or organizations. Locally, for example, McSweeney (2020) notes the lack of SFD research with parents and his study valuably points to the wider (and perhaps cultural) potential for "reverse socialization" of parents as a result of their children's involvement in SFD. Research with national policy makers is also limited and further research with individuals working for international organizations may consider the extent of their agency in navigating and potentially modifying the broader structural conditions that are recognized as constraining SFD.

Archer's work can also bring benefit to SFD research through enabling social change to be conceptualized as a process that occurs across cycles of three temporal phases. Spaaij et al. (2016) and Sabbe et al. (2020) both suggest that the full impact of SFD activities may not have emerged by the conclusion of their research. Similarly, Lindsey et al.'s (2017) research in Zambia identified how involvement in SFD programs had resulted in reappraisal of cultural norms among some groups of young women but that "more time is required for such collectives to build across other SFD sites and to mobilize effectively to lead to changes in existing social and cultural dynamics" (p. 178). In both cases, it appears uncertain as to whether the research came to an end while sociocultural interactions at Phase 2 were still occurring or whether Phase 3 had been reached, in which the completion of a cycle would enable a more certain appraisal of the extent of morphogenesis (change) or morphostasis (reproduction). A succinct recommendation would therefore be to design SFD research on transformative social change that can seek to differentiate social conditions between Phase 1 and Phase 3 of the morphogenetic/ morphostatic cycle. Moreover, additional consideration may also be given as to whether and how subsequent SFD activity could result in the commencement of further morphogenetic cycles which, again, could build on changes to social conditions or ultimately "fizzle out" into social reproduction to different extents.

In closing, it is important to note that this article represents a starting point for endeavors toward a foundational social ontology that supports improvements in research examining how SFD could 
potentially contribute to transformative social change. Developing empirical research based on the Morphogenetic Approach would also be an important step toward considering how the conceptualizations offered could inform practical thinking about the development of SFD policies, programs, and practices. As such, we are optimistic but cannot be definitive regarding the actual realization of the benefits of applying Archer's Morphogenetic Approach to the SFD work undertaken by researchers, practitioners, and policy makers. Challenges to the approach that we have outlined in this article could exist in the form of both theoretical criticisms of Archer's Morphogenetic Approach and real-world applications that could demonstrate the challenges, as well as benefits, of Archerinformed SFD research. Scrutiny on both fronts is important and welcome but, at the very least, we hope to have brought new insights and impetus to debates about the foundational assumptions upon which further progress in understanding SFD needs to be based.

\section{Note}

1. It is vital to recognize that the binary labels of positivism and interpretivism do not capture the range of paradigmatic positions used by SFD researchers, such as participatory or feminist epistemologies (e.g., Collison \& Marchesseault, 2018; Hayhurst, Giles, \& Radforth, 2015; Oxford \& Spaaij, 2019).

\section{References}

Archer, M. S. (1982). Morphogenesis versus Structuration: On Combining Structure and Action. The British Journal of Sociology, 33(4), 455-483.

Archer, M. S. (1995). Realist social theory: The morphogenetic approach. Cambridge: Cambridge University Press.

Archer, M. S. (2003). Structure, agency and the internal conversation. Cambridge University Press.

Archer, M. S. (2013). Realism and Morphogenesis. In Archer, M., Bhaskar, R., Collier, A., Lawson, T., \& Norrie, A. (eds.) Critical realism: Essential readings. London: Routledge.

Archer, M. S. (2016). Reconstructing Sociology: The Critical Realist Approach. Journal of Critical Realism, 15(4), 425-431.

Archer, M., Bhaskar, R., Collier, A., Lawson, T., \& Norrie, A. (eds.) (2013). Critical realism: Essential readings. London: Routledge.

Bhaskar, R. (1975). A Realist Theory of Science. London: Routledge.

Bhaskar, R. (1979). The Possibility of Naturalism: A Philosophical Critique of the Contemporary Human Sciences. London: Routledge.

Black, D. R. (2017). The challenges of articulating 'top down'and 'bottom up'development through sport. Third World Thematics: A TWQ Journal, 2(1), 7-22.

Byers, T. (2013). Using Critical Realism: A New Perspective on Control of Volunteers in Sport Clubs. European Sport Management Quarterly, 13(1), 5-31. 
Case, J.M., (2015). A social realist perspective on student learning in higher education: the morphogenesis of agency. Higher Education Research and Development, 34(5), 841-852.

Clark, A., P. MacIntyre, and J. Cruickshank. (2007). A Critical Realist Approach to Understanding and Evaluating Heart Health Programmes. Health, 11(4), 513-539

Coakley, J. (2011). Youth sports: What counts as “positive development?". Journal of Sport and Social Issues, 35(3), 306-324.

Coalter, F. (2010). Sport-for-development: going beyond the boundary? Sport in Society, 13(9), 13741391.

Coalter, F. (2013). Sport for development: What game are we playing? Abingdon: Routledge.

Collison, H., \& Marchesseault, D. (2018). Finding the missing voices of sport for development and peace (SDP): Using a 'Participatory social interaction research'methodology and anthropological perspectives within African developing countries. Sport in Society, 21(2), 226242.

CRN. (2020). Critical Realism Network [online]. Accessed January 102020. http://criticalrealismnetwork.org/

CSO. (2020). The Centre for Social Ontology [online]. Accessed January 10 2020].http://socialontology.org/

Danermark, B., Ekstrom, M. \& Jakobsen, L. (2005). Explaining society: An introduction to critical realism in the social sciences. London: Routledge.

Dao, M., \& Smith, T. (2019). The Capability Approach as a Conceptual Bridge for Theory-Practice in Sport-for-Development. Journal of Global Sport Management, DOI: 10.1080/24704067.2019.1703117

Darnell, S. (2012). Sport for development and peace: A critical sociology. London: Bloomsbury Academic.

Darnell,C., \& Dao, M. (2017). Considering sport for development and peace through the capabilities approach. Third World Thematics: A TWQ Journal, 2(1), 23-36.

Darnell, S. C., Field, R., \& Kidd, B. (2019). The history and politics of sport-for-development. London: Palgrave Macmillan.

Darnell, S. C., Giulianotti, R., Howe, P. D., \& Collison, H. (2018). Re-assembling sport for development and peace through actor network theory: Insights from Kingston, Jamaica. Sociology of sport journal, 35(2), 89-97.

Darnell,S.C., \& Hayhurst, L. M. (2011). Sport for decolonization: Exploring a new praxis of sport for development. Progress in development studies, 11(3), 183-196.

Downward, P. (2005). Critical (Realist) Reflection on Policy and Management Research in Sport, Tourism and Sports Tourism. European Sport Management Quarterly, 5(3), 303-320.

Elder-Vass, D. (2010). The Causal Power of Social Structures: Emergence, Structure and Agency. Cambridge: Cambridge University Press.

Forde, S. D. (2014). Look after yourself, or look after one another? An analysis of life skills in sport for development and peace HIV prevention curriculum. Sociology of Sport Journal, 31(3), $287-$ 303.

Fuller, C. W., Junge, A., DeCelles, J., Donald, J., Jankelowitz, R., \& Dvorak, J. (2010). 'Football for Health' - a football-based health-promotion programme for children in South Africa: a parallel cohort study. British Journal of Sports Medicine, 44(8), 546-554.

Harris, K., \& Adams, A. (2016). Power and discourse in the politics of evidence in sport for development. Sport management review, 19(2), 97-106. 
Hartmann, D. \& Kwauk, C. (2011). Sport and development: An overview, critique, and reconstruction. Journal of sport and social issues, 35(3), 284-305.

Hasselgård, A., \& Straume, S. (2015). Sport for development and peace policy discourse and local practice: Norwegian sport for development and peace to Zimbabwe. International journal of sport policy and politics, 7(1), 87-103.

Hayhurst, L. M. (2009). The power to shape policy: Charting sport for development and peace policy discourses. International journal of sport policy and politics, 1(2), 203-227.

Hayhurst, L. M., Giles, A. R., \& Radforth, W. M. (2015). 'I want to come here to prove them wrong': using a post-colonial feminist participatory action research (PFPAR) approach to studying sport, gender and development programmes for urban Indigenous young women. Sport in society, 18(8), 952-967.

Holt, N. L., Neely, K. C., Slater, L. G., Camiré, M., Côté, J., Fraser-Thomas, J., ... \& Tamminen, K. A. (2017). A grounded theory of positive youth development through sport based on results from a qualitative meta-study. International Review of Sport and Exercise Psychology, 10(1), 1-49.

Horrocks, I. (2009). Applying the Morphogenetic Approach. Journal of Critical Realism, 8(1), 35-62.

Lincoln, Y., Lynham, S., Guba, E. (2017). In Denzin, N. K \& Lincoln, Y. (eds.) Handbook of Qualitative Research, 5th ed. London: Sage, pp. 108-150.

Lindsey, I., Kay, T., Jeanes, R., \& Banda, D. (2017). Localizing Global Sport for Development. Manchester: Manchester University Press.

Lusted, J. (2018). A critical realist morphogenetic approach to researching sport policy: reflections on a large- scale study of policy implementation in grassroots English football. International Journal of Sport Policy and Politics, 10(4), 705-719.

McSweeney, M. (2020). Looking beyond the "intended beneficiary": parent experiences and perspectives of child participation in sport-for-development programs at an inner-city Toronto sport facility. Managing Sport and Leisure, 1-17.McSweeney, M., Kikulis, L., Thibault, L., Hayhurst, L., \& van Ingen, C. (2019). Maintaining and disrupting globalNorth hegemony/global-South dependence in a local African sport for development organisation: The role of institutional work. International Journal of Sport Policy and Politics, 11(3), 521-537.

McSweeney, M., \& van Luijk, N. (2019). Leaving the comfort zone: Utilizing institutional ethnography in sport for development and peace research. Qualitative Research in Sport, Exercise and Health, 11(4), 559-572.

Mirani, R. (2013). A case study of morphogenetic change in long-term offshoring. International Journal of Information Management, 33, 663-673.

Mwaanga, O., \& Banda, D. (2014). A postcolonial approach to understanding sport-based empowerment of people living with HIV/AIDS (PLWHA) in Zambia: The case of the cultural philosophy of Ubuntu. Journal of Disability \& Religion, 18(2), 173-191.

Nichol, A. J., Hall, E. T., Vickery, W., \& Hayes, P. R. (2019). Examining the relationships between coaching practice and athlete "outcomes": A systematic review and critical realist critique. International Sport Coaching Journal, 6(1), 13-29.

Nols, Z., Haudenhuyse, R. \& Theeboom, M. (2017). Urban sport-for-development initiatives and young people in socially vulnerable situations: Investigating the 'deficit model'. Social Inclusion, 5(2), 210-222.

Nols, Z., Haudenhuyse, R., Spaaij, R. \& Theeboom, M. (2019). Social change through an urban sport for development initiative? Investigating critical pedagogy through the voices of young people. Sport, Education and Society, 24(7), 727-741. 
Oxford, S. \& Spaaij, R. (2017). Critical pedagogy and power relations in sport for development and peace: lessons from Colombia. Third World Thematics: A TWQ Journal, 2(1), 102116.

Oxford, S., \& Spaaij, R. (2019). Gender relations and sport for development in Colombia: A decolonial feminist analysis. Leisure Sciences, 41(1-2), 54-71.

Patriksson, M. (1995). Scientific review part 2. In The significance of sport for society-Health, socialisation, economy: A scientific review, prepared for the 8th conference of European ministers responsible for sport, Lisbon, 17-18 May. Strasbourg: Council of Europe Press.

Porpora D.V. (2013) Morphogenesis and Social Change. In Archer, M. S. (eds) Social Morphogenesis. Springer, Dordrecht. pp. 25-37.

Porpora, D. V. (2015). Reconstructing sociology: The critical realist approach. Cambridge University Press.

Pringle, R. \& M. Falcous. (2016). "Transformative Research and Epistemological Hierarchies: Ruminating on How the Sociology of the Sport Field Could Make More of a Difference." International Review for the Sociology of Sport 53 (3): 261-277.

Ryba, T. V., Wiltshire, G., North, J., \& Ronkainen, N. J. (2020). Developing mixed methods research in sport and exercise psychology: potential contributions of a critical realist perspective. International Journal of Sport and Exercise Psychology, 1-21.

Sabbe, S., Bradt, L., Spaaij, R. \& Roose, R. (2020). Community sport and social cohesion: in search of the practical understandings of community sport practitioners in Flanders. Community Development Journal, 55(2), 258-276.

Sabbe, S., Roose, R. \& Bradt, L. (2019). Tipping the balance back towards emancipation: exploring the positions of Flemish community sport practitioners towards social control. Sport in Society, 22(6), 950-965.

Schulenkorf, N., Edwards, D. \& Hergesell, A. (2020). Guiding qualitative inquiry in sport-fordevelopment: The sport in development settings (SPIDS) research framework. Journal of Sport for Development.

Seal, M. (2016). Critical realism's potential contribution to critical pedagogy and youth and community work: Human nature, agency and praxis revisited. Journal of Critical Realism, 15(3), 263-276.

Seal, E. \& Sherry, E. (2018). Exploring empowerment and gender relations in a sport for development program in Papua New Guinea. Sociology of Sport Journal, 35(3), 247-257.

Spaaij, R. \& Jeanes, R. (2013). Education for social change? A Freirean critique of sport for development and peace. Physical Education and Sport Pedagogy, 18(4), 442-457.

Spaaij, R., Oxford, S. \& Jeanes, R. (2016). Transforming communities through sport? Critical pedagogy and sport for development. Sport, education and society, 21(4), 570-587.

Sugden, J. (2010). Critical Left-Realism and Sport Interventions in Divided Societies. International Review for the Sociology of Sport 45(3), 258-272.

Suzuki, N. (2017). A capability approach to understanding sport for social inclusion: Agency, structure and organisations. Social Inclusion, 5(2), 150-158.

Svensson, P. G., \& Levine, J. (2017). Rethinking sport for development and peace: The capability approach. Sport in Society, 20(7), 905-923.

Whitley, M. A., Massey, W. V., Camiré, M., Blom, L. C., Chawansky, M., Forde, S., ... \& Darnell, S. C. (2019). A systematic review of sport for development interventions across six global cities. Sport Management Review, 22(2), 181-193. 
Wiltshire, G. (2018). A case for critical realism in the pursuit of interdisciplinarity and impact. Qualitative Research in Sport, Exercise and Health, 10(5), 525-542.

Wong, G., Greenhalgh, T., Westhorp, G. \& Pawson, R. (2012). Realist methods in medical education research: what are they and what can they contribute? Medical Education, 46, 89-96.

Zipp, S., Smith, T. \& Darnell, S. (2019). Development, gender and sport: Theorizing a feminist practice of the capabilities approach in sport for development. Journal of Sport Management, 33(5), 440-449. 


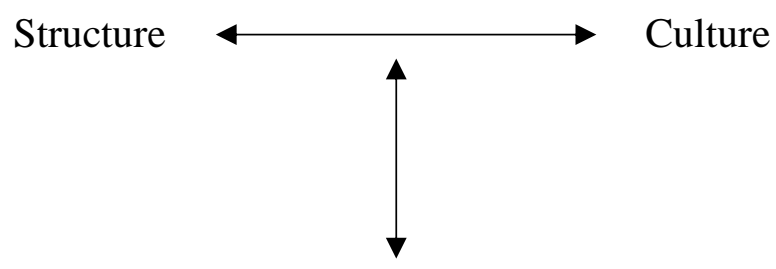

Agency

Figure 1. Structure, culture and agency are distinctive in the morphogenetic approach

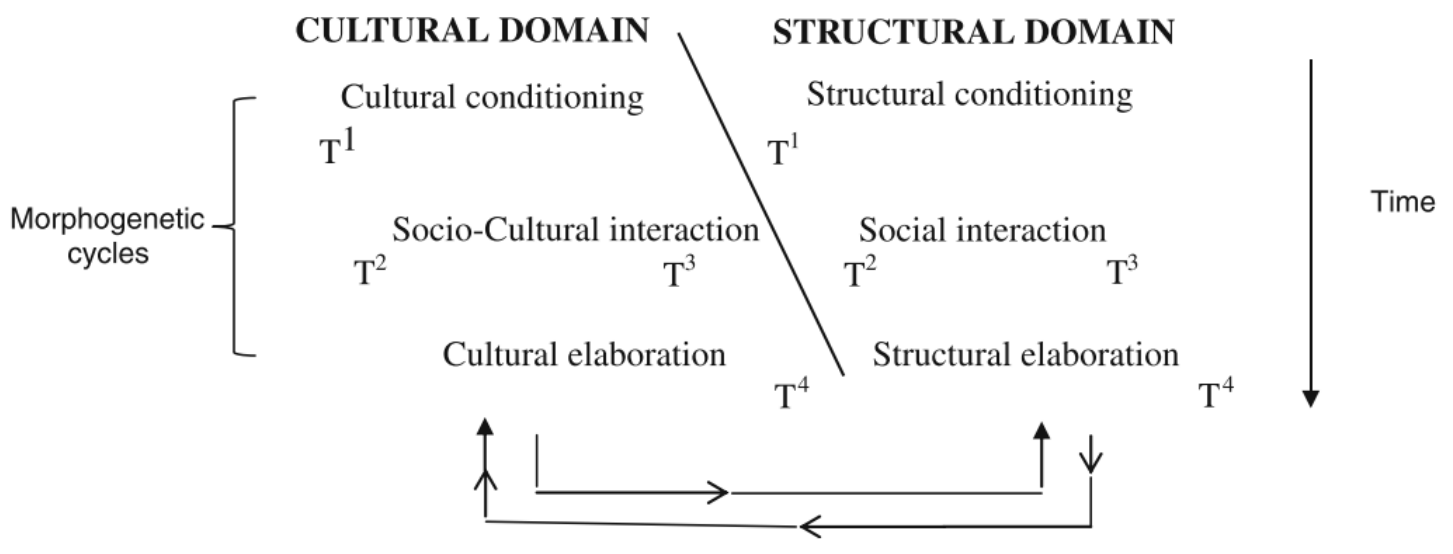

Figure 2. Morphogenesis/stasis with both structure and culture (Archer, 1995, p323) 